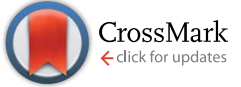

Cite this: RSC Adv., 2017, 7, 12144

\title{
Antibacterial and catalytic activities of biosynthesized silver nanoparticles prepared by using an aqueous extract of green coffee bean as a reducing agent
}

\begin{abstract}
Mengmeng Wang, ${ }^{a}$ Wenjing Zhang, ${ }^{a}$ Xuesong Zheng*b and Peizhi Zhu*a
Spherical biogenic silver nanoparticles (AgNPs) were synthesized using aqueous green coffee bean extract as a reducing agent. The green coffee bean extract was used for the time to reduce silver ions via a onestep, green, and rapid approach. The prepared AgNPs were characterized via transmission electron microscopy (TEM), atomic force microscopy (AFM), and UV-visible spectroscopy. Dynamic light scattering (DLS) was performed to measure the particle size. These AgNPs exhibit strong antibacterial activity against both Gram-negative and Gram-positive bacteria and the minimum inhibitory concentration (MIC) of AgNPs for Escherichia coli and Staphylococcus aureus are $0.05 \mu \mathrm{mol} \mathrm{L} \mathrm{L}^{-1}$ and 0.1 $\mu \mathrm{mol} \mathrm{L} L^{-1}$, respectively. Furthermore, AgNPs could serve as an effective catalyst for the reduction of 4-nitrophenol to 4-aminophenol in the presence of $\mathrm{NaBH}_{4}$.
\end{abstract}

Received 3rd December 2016 Accepted 4th February 2017

DOI: $10.1039 / c 6 r a 27706 c$

rsc.li/rsc-advances

play a key role in the chemical industries; among these, silver nanoparticles have gained significant attention owing to their unique electronic properties and high surface to volume ratio. ${ }^{22}$ In addition, silver nanocatalysts are cost-effective, efficient, and environmentally friendly. In particular, silver nanoparticles present highly efficient catalytic activity in the oxidation of methanol and ethylene, ${ }^{23,24}$ as well as in the reduction of nitric oxides $\left(\mathrm{NO}_{x}\right) \cdot{ }^{25}$

For the synthesis of silver nanoparticles, a variety of methods have been employed such as chemical reduction, ${ }^{26}$ electrochemical process, ${ }^{27}$ microemulsion method, ${ }^{28}$ laser ablation, ${ }^{29}$ and hydrothermal method. ${ }^{30}$ Chemical reduction is still the most common method. Recently, inspired by the concept of green chemistry, several studies have been focussed on the development of novel eco-friendly reducing agents for synthesizing AgNPs. Many interesting biomolecules including those obtained from plant extract, ${ }^{31-33}$ bacteria, ${ }^{34}$ viruses,${ }^{35}$ DNA,${ }^{36}$ and peptides $^{37-39}$ have been used to successfully synthesize AgNPs. ${ }^{40}$

In this study, we report the synthesis of silver nanoparticles using green coffee bean extract as a reducing agent for the first time. Green coffee bean extracts were obtained from the seeds of Coffea arabica, Coffea canephora, and Coffea liberica. Green coffee bean extracts have been used as a healthy food supplement for long time because the main ingredient chlorogenic acid is a native antioxidant and can reduce blood pressure. We used TEM, AFM, and DLS to characterize the morphology and particle size of the silver nanoparticles synthesized using green coffee bean extracts. The formation of silver nanoparticles was studied by UV-visible spectroscopy. In antibacterial experiments, Escherichia coli and Staphylococcus aureus were used to 
evaluate the antimicrobial activity of AgNPs against Gramnegative and Gram-positive bacteria, respectively. Moreover, the catalytic activity of the as-prepared silver nanoparticles for the reduction of 4-nitrophenol in the presence of $\mathrm{NaBH}_{4}$ was also studied.

\section{Materials and methods}

\section{Chemicals and materials}

Silver nitrate $\left(\mathrm{AgNO}_{3}, 99.8 \%\right)$, 4-nitrophenol (4-NP), sodium borohydride $\left(\mathrm{NaBH}_{4}, 98 \%\right)$ were purchased from Sinopharm Chemical Reagent Co. Ltd (Shanghai, China). Green coffee bean extracts were purchased from Xi'an Zebang Biological Technology Co. Ltd. Chlorogenic acid (CGA, 98\%) was purchased from Bioduly Biochemical Reagent (Nanjing, China). All the chemicals were of analytical reagent grade and were used without further purification. All the solutions were freshly prepared using deionized double-distilled water.

\section{Preparation of silver nanoparticles}

For the biosynthesized silver nanoparticles, $0.2175 \mathrm{~g}$ silver nitrate was dissolved in $15 \mathrm{~mL}$ deionized double-distilled water. Then, $25 \mathrm{~mL}$ of a $1 \mathrm{mM}$ aqueous green coffee bean extract solution was added dropwise to a silver nitrate solution under stirring at $30{ }^{\circ} \mathrm{C}$. To ensure a complete mixing, stirring was maintained for 5 minutes. The color of the as-prepared silver nanoparticles appeared similar to that of the green coffee bean extracts solution. The synthesis of CGA-AgNPs was performed in a water-based system; $2.8 \mathrm{~mL}$ of $0.5 \mathrm{mM} \mathrm{AgNO}_{3}$ was placed in a glass vial with a cap and heated to $80^{\circ} \mathrm{C}$ on a hot plate under stirring for $3 \mathrm{~min}$. A $1.2 \mathrm{~mL}$ of $0.05 \mathrm{mM}$ CGA was added dropwise under stirring on a hot plate within $2 \mathrm{~min}$. Then, the reaction mixture was further incubated in an oven for $10 \mathrm{~h}$.

\section{TEM analysis of the silver nanoparticles}

Transmission electron microscopy (TEM, Tecnai C2 F30 S-Twin, FEI, USA) was used to observe the morphologies and particle sizes of AgNPs, and selected-area electron diffraction (SAED) patterns were obtained via high-resolution transmission electron microscopy (HRTEM). Transmission electron microscopy was performed by fixation on a 200-mesh carbon-coated copper grid.

\section{UV-visible spectra analysis}

The absorbance spectra of AgNPs and CaP-coated AgNPs were obtained by UV-Vis spectroscopy (Varian Cary 500, USA).

\section{Dynamic light scattering measurement}

The particle size distribution of the biosynthesized AgNPs was analyzed using a Zetasizer Nanoseries apparatus (Malvern) with laser $\mathrm{He}-\mathrm{Ne}(4 \mathrm{~mW})$ at $632.8 \mathrm{~nm}$.

\section{Atomic force microscope analysis}

AFM (Bruker, Santa Barbara, CA) images were obtained using Shimadzu nano search microscope SFT-3500 in QNM (quantitative nanomechanical mapping) mode. The typical resonance frequency of the cantilever with an integrated silicon tip (spring constant $40 \mathrm{~N} \mathrm{~m}^{-1}$ ) was between 283.8 and $360 \mathrm{kHz}$.

\section{Antibacterial test}

The antibacterial activity of the synthesized AgNPs was tested by growth inhibition curve method, and the minimum inhibitory concentration (MIC) was also determined. The assay was performed on Escherichia coli (ATCC 25922) and Staphylococcus aureus (ATCC 25923), which acted as the representatives for Gram-negative and Gram-positive bacteria, respectively.

First, the suspension solutions of $E$. coli and $S$. aureus were prepared by shaking in an incubator at $37^{\circ} \mathrm{C}$ for $8 \mathrm{~h}$. The AgNPs solutions of various concentrations were prepared by diluting the nanosilver solution of $50 \mu \mathrm{mol} \mathrm{L}^{-1}$ with double-distilled $\mathrm{H}_{2} \mathrm{O}$. Then, $100 \mu \mathrm{L}$ of AgNPs solutions and $900 \mu \mathrm{L}$ of LB were completely mixed in $1.5 \mathrm{~mL}$ microcentrifuge tubes. The tube of $\mathrm{ddH}_{2} \mathrm{O}$ in place of the AgNPs solution in the mixture was used as the control. Therefore, the final concentration of AgNPs in the media were $0.5 \mu \mathrm{mol} \mathrm{L}^{-1}, 0.2 \mu \mathrm{mol} \mathrm{L}^{-1}, 0.1 \mu \mathrm{mol} \mathrm{L}^{-1}, 0.05$ $\mu \mathrm{mol} \mathrm{L}{ }^{-1}, 0.04 \mu \mathrm{mol} \mathrm{L}^{-1}, 0.03 \mu \mathrm{mol} \mathrm{L}^{-1}, 0.02 \mu \mathrm{mol} \mathrm{L}^{-1}, 0.01$ $\mu \mathrm{mol} \mathrm{L}{ }^{-1}$, and $0.005 \mu \mathrm{mol} \mathrm{L}^{-1}$. Two hundred microliters of the mixture was transferred with pipette into each well of a Corning 96-well microtiter plate and $2 \mu \mathrm{L}$ of a bacteria suspension solution was inoculated in each well. Immediately, this plate was incubated at $37^{\circ} \mathrm{C}$ for $180 \mathrm{~min}$ in Multimode Plate-Reader (Tecan infinite 200PRO). The $\mathrm{OD}_{600}$ values were measured at the intervals of $5 \mathrm{~min}$, following $20 \mathrm{~s}$ plate-shaking every time.

\section{Catalytic reduction of 4-nitrophenol}

In a typical run for the reduction of 4-NP by NaBH4, $0.2 \mathrm{~mL}$ of biosynthesized silver nanoparticles $(1 \mathrm{mM})$ was added to $5 \mathrm{~mL}$ reaction solution containing $0.05 \mathrm{mmol}$ fresh solution of 4-NP and $0.2 \mathrm{mmol} \mathrm{NaBH}_{4}$ solution. To set a blank group, the reaction system was kept same as the abovementioned system except that the prepared silver nanoparticles were replaced by ultra-pure water. The reaction in the presence of $\mathrm{NaBH}_{4}$ was immediately monitored by UV-visible spectrophotometric monitoring instrument over a $210-600 \mathrm{~nm}$ wavelength.

\section{Results and discussion}

\section{Characterization of the biosynthesized silver nanoparticles}

TEM was carried out to investigate the morphology and size of the obtained AgNPs. Fig. 1a, d and e shows typical TEM images of the AgNPs and most AgNPs nanoparticles were well-dispersed in the solution of green coffee bean extract. Fig. 1a and b shows that the nanoparticles were spherical in shape. The highresolution TEM image, as shown in Fig. 1c, shows polycrystalline structure of the particles. From Fig. 1d, clear lattice fringes can be easily observed, and the interplanar spacing of these was measured to be $0.209 \mathrm{~nm}$ that corresponds to the $\mathrm{Ag}$ (200) plane. $^{31}$ The selected-area electron diffraction (SAED) pattern, as shown in Fig. 1e, proves the polycrystalline structure of the synthesized AgNPs, which is consistent with the TEM result. The AFM topography image (Fig. 1f and g) shows that the 

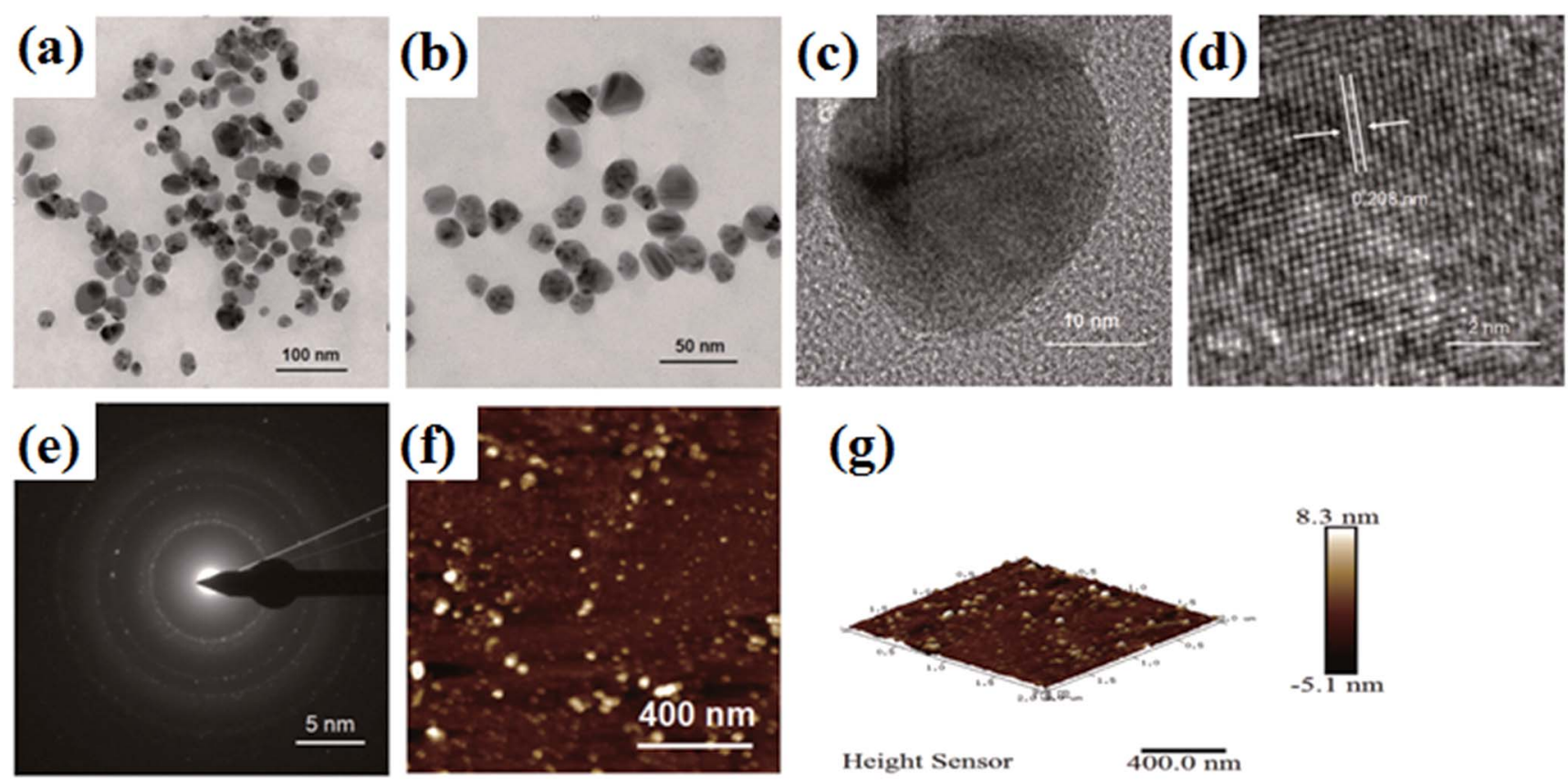

(g)

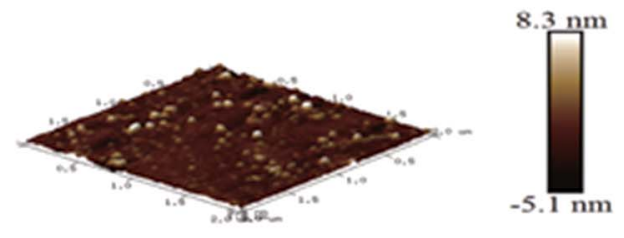

Height Sensor $\quad 4 \overline{00.0 \mathrm{~nm}}$

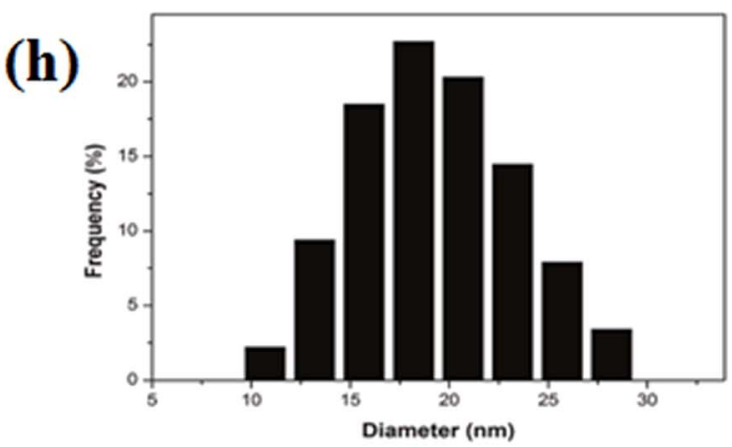

(i)

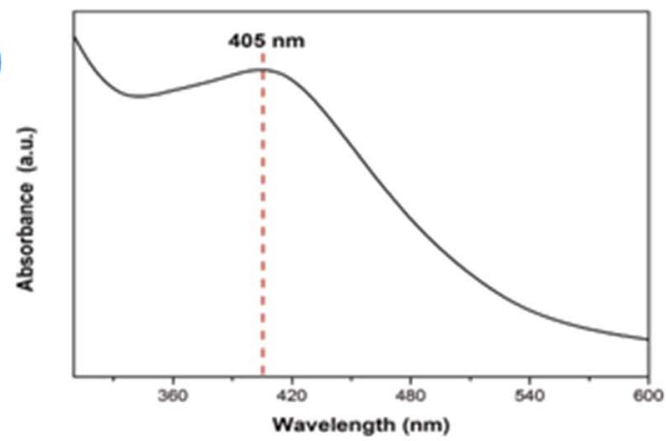

Fig. 1 HRTEM (a-d) images and SAED pattern (e) of the AgNPs. AFM (f and g) images of the biosynthesized silver nanoparticles. (h) Sizedistribution histogram of the biosynthesized AgNPs. (i) UV-vis spectrum of the biosynthesized AgNPs.

size of AgNPs ranges from 10 to $30 \mathrm{~nm}$ in diameter, which is consistent with the DLS histogram (Fig. 1h). Fig. 1i displays the UV-vis absorption spectra of the as-prepared AgNPs. An obvious absorption peak at $405 \mathrm{~nm}$, as shown in Fig. 1i, confirmed the formation of AgNPs since the characteristic silver SPR (surface plasmon resonance) bands are around $400-450 \mathrm{~nm}^{41}$

\section{Antibacterial properties of the biosynthesized AgNPs}

The 180 min growth curve for E. coli and S. aureus in LB media containing various concentrations of AgNPs are displayed in Fig. 2. Based on these curves, the excellent antibacterial activity of the AgNPs against both Gram-negative and Gram-positive bacteria can be concluded, and the minimum inhibitory concentration (MIC) (MIC $=0.04 \mu \mathrm{mol} \mathrm{L}^{-1}$ for $E$. coli and 0.2 $\mu \mathrm{mol} \mathrm{L}{ }^{-1}$ for $S$. aureus) can be determined. For E. coli (Fig. 2a), the concentration of $0.02 \mu \mathrm{mol} \mathrm{L}{ }^{-1}$ AgNPs exhibited a weak growth inhibition. During $180 \mathrm{~min}$ of the assay, $0.05 \mu \mathrm{mol} \mathrm{L}{ }^{-1}$ AgNPs absolutely repressed the bacterial growth. However, for $S$. aureus (Fig. 2b), $0.05 \mu \mathrm{mol} \mathrm{L}^{-1}$ AgNPs just slightly repressed the growth and the absolute inhibition concentration was approximately $0.1 \mu \mathrm{mol} \mathrm{L}{ }^{-1}$.

This difference may be due to the difference in the bacterial cell wall structure. Shrivastava et al. elucidated in their study that the different cell wall structure leads to variety in the penetration of AgNPs. ${ }^{42}$ The cell wall of the Gram-positive bacteria is composed of a thick layer of peptidoglycan that constitutes linear polysaccharides chains cross-linked by short peptides, thus forming a rigid structure. This leads to difficulty in the penetration of AgNPs compared to that for Gram-negative bacteria, where the cell wall possesses a much thinner layer of peptidoglycan.

\section{Catalytic reduction of 4-nitrophenol}

The reduction of 4-nitrophenol by $\mathrm{NaBH}_{4}$ was taken as a model reaction to examine the catalytic activity of the AgNPs. The absorption peak of 4-NP with a light yellow color shifted from $317 \mathrm{~nm}$ to $400 \mathrm{~nm}$ after the addition of freshly prepared $\mathrm{NaBH}_{4}$ solution. This is due to the presence of $\mathrm{NaBH}_{4}$ that changed the 
(a)
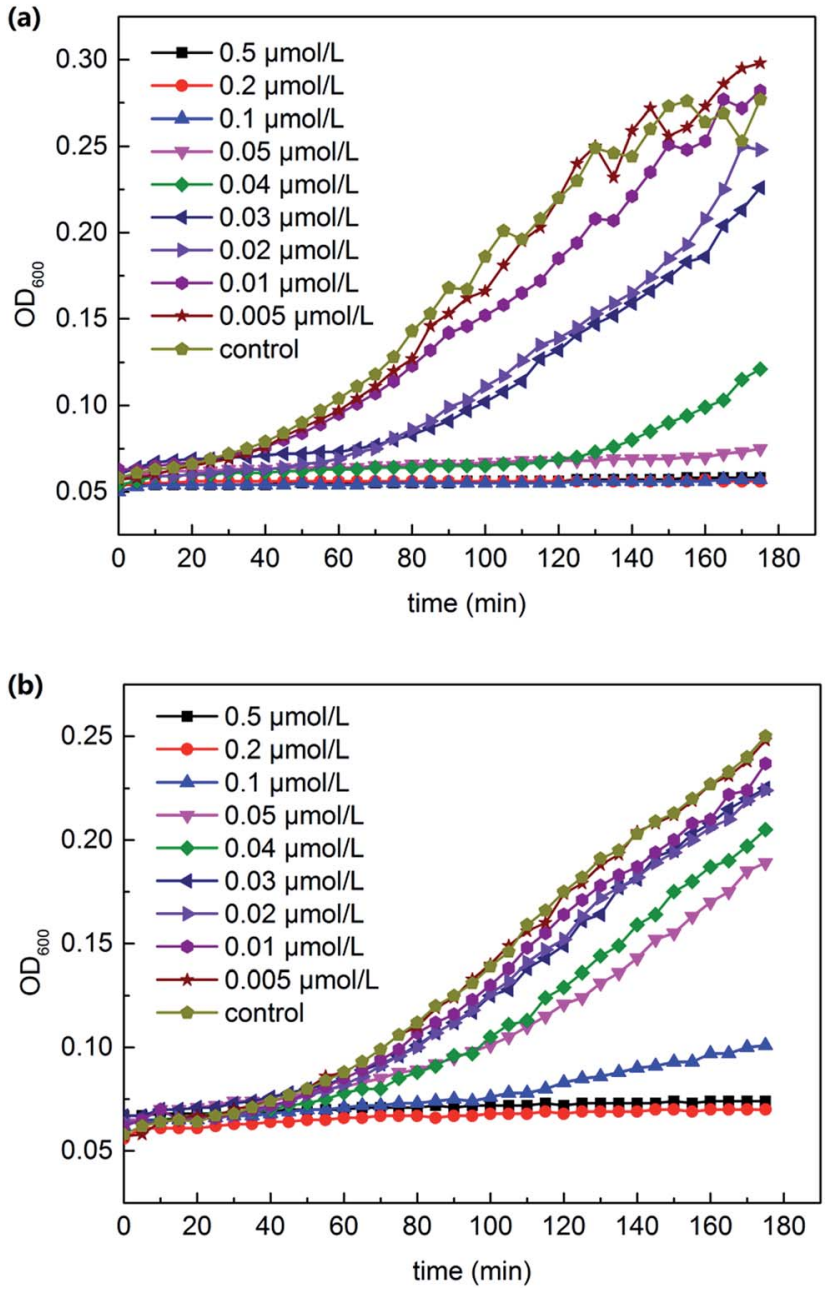

Fig. 2180 min growth curve for E. coli (a) and S. aureus (b) in LB media containing various concentrations of AgNPs.

$\mathrm{pH}$ of the solution. ${ }^{43}$ Moreover, the light yellow color turned to intense yellow, indicating the formation of 4-nitrophenolate ion.

The catalytic process of this reaction was monitored by UVvis spectroscopy; the absorption intensity at $400 \mathrm{~nm}$ for 4nitrophenolate ion remained unvaried without the silver nanocatalyst. As shown in Fig. 3a, a new band at around $300 \mathrm{~nm}$ emerged after adding $2 \mathrm{~mL}$ AgNPs as a catalyst, indicating the reduction of 4-NP to 4-AP by $\mathrm{NaBH}_{4}$. Until the end of the reaction, the intensity of the absorption peak at $400 \mathrm{~nm}$ gradually decreased with time, whereas the absorption peak at $300 \mathrm{~nm}$ simultaneously increased. The kinetic process of the reduction was monitored by measuring the extinction of the solution at $400 \mathrm{~nm}$ as a function of time. A good linear correlation is shown in Fig. $3 \mathrm{~b}$ and the apparent rate constant $(K)$ of this catalytic reaction was $0.0456 \mathrm{~S}^{-1}$, suggesting that the biosynthesized AgNPs possessing a larger surface area exhibit high-effective catalytic activity for the reduction of 4-NP.

The main content of the green coffee bean is chlorogenic acid (CGA). However, we could not synthesize silver nanoparticles using only chlorogenic acid as a reducing agent at
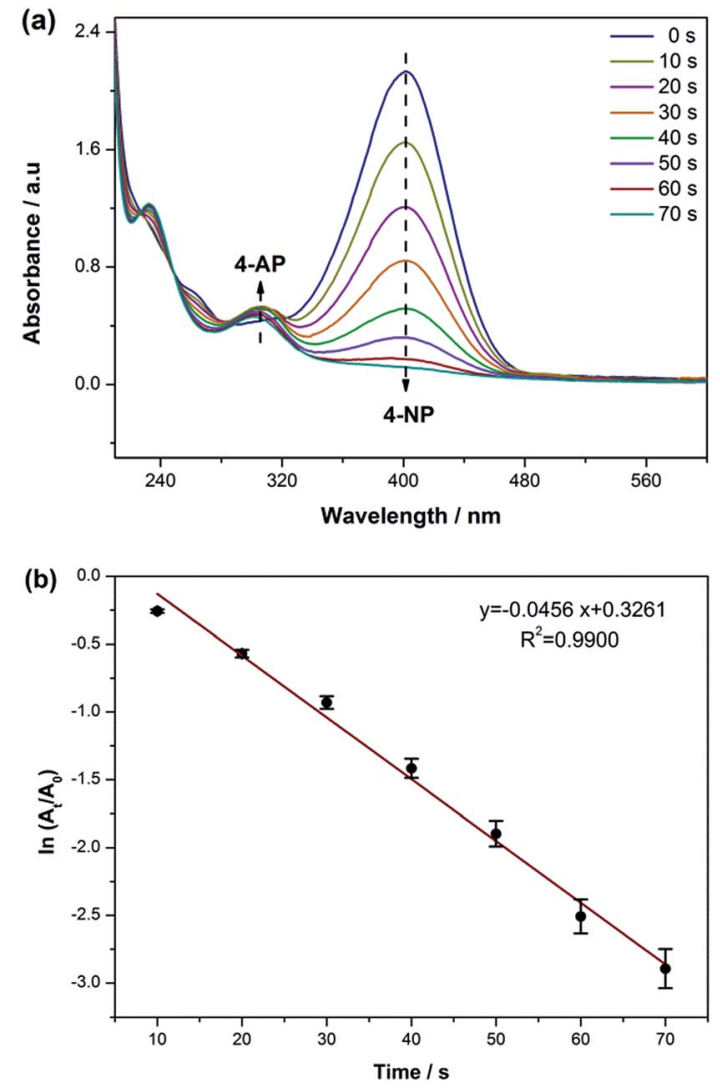

Fig. 3 (a) UV-vis spectra of the 4-NP reduction in the presence of $\mathrm{NaBH}_{4}$ and $0.2 \mathrm{~mL}$ biosynthesized AgNPs and (b) catalytic degradation curves of 4-NP over the biosynthesized AgNPs.

$30{ }^{\circ} \mathrm{C}$. Then, reaction temperature was increased by a step of every $10{ }^{\circ} \mathrm{C}$. The CGA-AgNPs were synthesized at $80^{\circ} \mathrm{C}$, which is consistent with the results of previous report. ${ }^{44}$ TEM images showed that the CGA-AgNPs were well-dispersed nanoparticles. The average particle sizes of the CGA-AgNPs were smaller than those of the AgNPs synthesized using aqueous green coffee bean extracts (Fig. 4). The synthesis of CGA-AgNPs showed that the reducing agent in the aqueous green coffee bean extracts was mainly chlorogenic acid. Green coffee bean extracts contain a variety of components such as caffeine, sucrose, citric acid, and trigonelline, many isomers of chlorogenic acid, amino

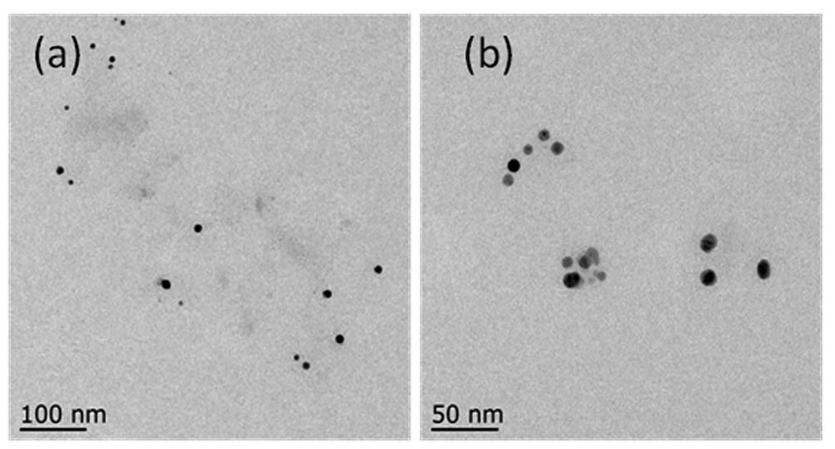

Fig. 4 TEM images of CGA-AgNPs. 
acids, etc. ${ }^{45}$ Chlorogenic acid is the main component in the green coffee bean extracts, which is accountable for the reduction of $\mathrm{Ag}^{+}$to $\mathrm{Ag}^{0}$ for the green synthesis of AgNPs. We hypothesized that other components, such as citric acid, can also act as reducing agents and the synergistic effect of several reducing agents lowered the energy barrier for the reduction of silver ions. These chemicals also act as capping agents to stabilize the synthesized silver nanoparticles. Since green coffee bean extract is much cheaper than chlorogenic acid, silver nanoparticles can be synthesized using a green coffee bean extract as a reducing agent at $30{ }^{\circ} \mathrm{C}$, which a much lower temperature than that required by chlorogenic acid only. This environmentally friendly approach is suitable for the large-scale biosynthesis of silver nanoparticles due to its operational simplicity, low-cost, and green conditions. These well-caped silver nanoparticles produced by the green coffee bean extract are more stable and can strongly inhibit the growth of both Gram-negative and Gram-positive bacteria. In addition, these silver nanoparticles have potential in the simple and safe reduction of phenol compounds in water.

\section{Conclusions}

In this study, biogenic spherical AgNPs were successfully synthesized using aqueous green coffee bean extracts for the first time. The approach was reproducible, cost-effective, and eco-friendly. TEM and DLS analysis showed that the particle size of the as-prepared silver nanoparticles ranged from $12 \mathrm{~nm}$ to $31 \mathrm{~nm}$. These small AgNPs exhibit strong antibacterial activity against $E$. coli and $S$. aureus and its MICs were evaluated to be $0.05 \mu \mathrm{mol} \mathrm{L}{ }^{-1}$ and $0.1 \mu \mathrm{mol} \mathrm{L}{ }^{-1}$, respectively. Moreover, biosynthesized silver nanoparticles could be an effective catalyst for the reduction of 4-nitrophenol to 4-aminophenol in the presence of $\mathrm{NaBH}_{4}$.

\section{Acknowledgements}

We would like to thank Jiangsu Province for specially appointed professorship to Professor Peizhi Zhu and Testing Center of Yangzhou University for the support. This work was also supported by the Priority Academic Program Development of Jiangsu Higher Education Institutions.

\section{Notes and references}

1 H. Lin, R. R. Zhang and Q. W. Chen, Nanoscale, 2014, 6, 14064-14105.

2 F. Hua, T. H. Cui and Y. M. Lvov, Nano Lett., 2004, 4, 823-825. 3 P. Ginzburg, N. Berkovitch, A. Nevet, I. Shor and M. Orenstein, Nano Lett., 2011, 11, 2329-2333.

4 X. L. Hu, G. S. Li and J. C. Yu, Langmuir, 2010, 26, 3031-3039. 5 W. Wang, T. Y. Chiang, D. Velego and T. E. Mallouk, J. Am. Chem. Soc., 2013, 135, 10557-10565.

6 B. H. Dong, C. Y. Li, G. C. Chen, Y. J. Zhang, Y. Zhang, M. J. Deng and Q. B. Wang, Chem. Mater., 2013, 25, 25032509.
7 M. X. Zhang, Y. H. Cao, Y. Chong, Y. F. Ma, H. L. Zhang, Z. W. Deng, C. H. Hu and Z. J. Zhang, ACS Appl. Mater. Interfaces, 2013, 5, 13325-13332.

8 S. Dasa and B. B. Dhar, RSC Adv., 2014, 4, 46285-46292.

9 M. S. Noh, B. H. Jun, S. Kim, H. Kang, M. A. Woo, A. MinaiTehrani, J. E. Kima, J. Kim, J. Y. Park, H. T. Lim, S. C. Park, T. Hyeon, Y. K. Kim, D. H. Jeong, Y. S. Lee and M. H. Cho, Biomaterials, 2009, 30, 3915-3925.

10 M. R. Reithofer, A. Lakshmanan, A. T. K. Ping and J. M. Chin, Biomaterials, 2014, 35, 7535-7542.

11 D. Kagan, P. Calvo-Marzal, S. Balasubramanian, S. Sattayasamitsathit, K. M. Manesh, G. U. Flechsig and J. Wang, J. Am. Chem. Soc., 2009, 131, 12082-12083.

12 Y. Yang, T. Liu, L. Cheng, G. S. Song, Z. Liu and M. W. Chen, ACS Appl. Mater. Interfaces, 2015, 7, 7526-7533.

13 P. Sanpui, A. Chattopadhyay and S. S. Ghosh, ACS Appl. Mater. Interfaces, 2011, 3, 218-228.

14 E. Y. Furuya and F. D. Lowy, Nat. Rev. Microbiol., 2006, 4, 3645.

15 S. A. Jones, P. G. Bowler, M. Walker and D. Parsons, Wound Repair Regen., 2004, 12, 288-294.

16 V. Prabu, P. Karthick, A. Rajendran, D. Natarajan, M. S. Kiran and D. K. Pattanayak, RSC Adv., 2015, 5, 50767-50777.

17 Z. Abdali, H. Yeganeh, A. Solouk, R. Gharibi and M. Sorayya, RSC Adv., 2015, 5, 66024-66036.

18 R. S. Chen, H. W. Ni, H. S. Zhang, G. Yue, W. T. Zhan and P. Y. Xiong, Vacuum, 2013, 89, 249-253.

19 A. M. Mittelman, D. S. Lantagne, J. Rayner and K. D. Pennell, Environ. Sci. Technol., 2015, 49, 8515-8522.

20 H. J. Klasen, Burns, 2000, 33, 117-138.

21 W. Lee, K. J. Kim and D. G. Lee, BioMetals, 2014, 27, 11911201.

22 L. Sintubin, W. D. Windt, J. Dick, J. Mast, D. vanderHa, W. Verstraete and N. Boon, Appl. Microbiol. Biotechnol, 2009, 84, 741-749.

23 E. Qayyum, V. A. Castillo, K. Warrington, M. A. Barakat and J. N. Kuhn, Catal. Commun., 2012, 28, 128-133.

24 M. J. Lippits and B. E. Nieuwenhuys, Catal. Today, 2010, 154, 127-132.

25 S. Wunder, F. Polzer, Y. Lu, Y. Mei and M. Ballauff, J. Phys. Chem. C, 2010, 114, 8814-8820.

26 Y. Sun and Y. Xia, Science, 2002, 298, 2176-2179.

27 C. D. Gu and T. Y. Zhang, Langmuir, 2008, 24, 12010-12016.

28 S. Pal, E. J. Yoon, Y. K. Tak, E. C. Choi and J. M. Song, J. Am. Chem. Soc., 2009, 131, 16147-16155.

29 H. S. Shin, H. J. Yang, S. B. Kim and M. S. Lee, J. Colloid Interface Sci., 2004, 274, 89-94.

30 M. Feng, M. Zhang, J. M. Song, X. G. Li and S. H. Yu, ACS Nano, 2011, 5, 6726-6735.

31 A. A. Kajani, A. K. Bordbar, S. H. Z. Esfahani, A. R. Khosropour and A. Razmjou, RSC Adv., 2014, 4, 61394.

32 S. Iravani, Green Chem., 2011, 13, 2638-2650.

33 S. K. Li, Y. H. Shen, A. J. Xie, X. R. Yu, L. G. Qiu, L. Zhang and Q. F. Zhang, Green Chem., 2007, 9, 852-858.

34 H. Zhang, Q. Li, Y. Lu, D. Sun, X. Lin, X. Deng, N. He and S. Zheng, J. Chem. Technol. Biotechnol., 2005, 80, 285-290. 
35 C. X. Yang, S. Jung and H. Yi, Biochem. Eng. J., 2014, 89, 1020.

36 S. Kundu, Phys. Chem. Chem. Phys., 2013, 15, 1107-14119.

37 K. T. Nam, Y. J. Lee, E. M. Krauland, S. T. Kottmann and A. M. Belcher, ACS Nano, 2008, 2, 1480-1486.

38 G. Upert, F. Bouillere and H. Wennemers, Angew. Chem., Int. Ed., 2012, 51, 4231-4234.

39 H. Wennemers, J. Pept. Sci., 2012, 18, 437-441.

40 P. R. Rathi Sre, M. Reka, R. Poovazhagi, M. Arul Kumar and K. Murugesan, Spectrochim. Acta, Part A, 2015, 135, 11371144.
41 E. C. Njagi, H. Huang, L. Stafford, H. Genuino, H. M. Galindo, J. B. Collins, G. E. Hoag and S. L. Suib, Langmuir, 2011, 27, 264-271.

42 S. Shrivastava, T. Bera, A. Roy, G. Singh, P. Ramachandrarao and D. Dash, Nanotechnol., 2007, 18, 225103-225122.

43 B. Baruah, G. J. Gabriel, M. J. Akbashev and M. E. Booher, Langmuir, 2013, 29, 4225-4234.

44 H. J. Noh, H. S. Kim, S. H. Jun, Y. H. Kang, S. Cho and Y. Park, J. Nanosci. Nanotechnol., 2013, 13, 5787-5793.

45 F. Wei, K. Furihata, F. Hu, T. Miyakawa and M. Tanokura, Magn. Reson. Chem., 2010, 48, 857-865. 